\title{
Mythos Rom
}

Erhard Taverna

erhard.taverna[at]saez.ch
Die Stadt ist eine Zumutung. Raum-Zeit-Koloss, baugeschichtliches Korallenriff, Flanier- und Marktparadies, abgasverseucht, chaotisch, fromm und kriminell. Die Reiseliteratur ist unübersehbar, doch Grabungen kommen fast immer darin vor. Nach langer Bauzeit ist im November die dritte Metropolitana, von San Pietro nach Prati, eröffnet worden. Ein technisches Wunderwerk, ein Drittel der Strecke unterir-

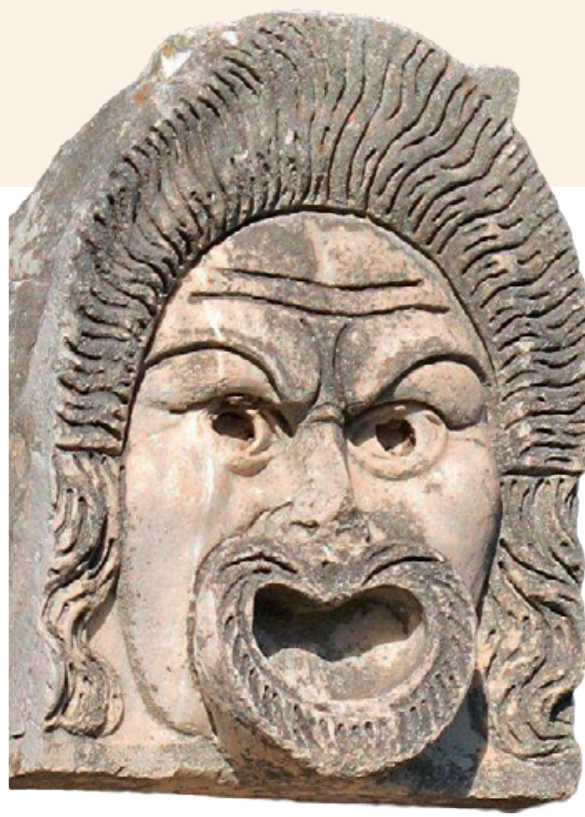
disch, ein geldverschlingendes Monster, ein Alptraum für Archäologen.

Allein das Colosseum zieht jährlich fünf Millionen Besucher an. Neue Funde werden zugänglich und visuell aufbereitet. Zum Beispiel zwei luxuriöse Stadthäuser des 4. nachchristlichen Jahrhunderts unter dem Kellergeschoss des Palazzo Valentini. Die kleinen Besuchergruppen gehen im Halbdunkel auf Glasböden über die freigelegten Ruinen. Im Scheinwerferlicht leuchten die kommentierten Gegenstände auf. Thermen, Mosaikböden und Wandfliesen wachsen in virtueller Perfektion zu intakten Räumen mit Aussicht auf Garten und Nachbarhäuser empor. Durch einen Bunkergang rückt die Siegessäule Trajans in greifbare Nähe. Der abschliessende Film erklärt einzelne Reliefszenen aus dem Spiralband, Militärkampagnen in Dakien, die Eroberung Rumäniens. Einen ruhigeren Gegenpol zu dieser elektronischen Inszenierung im Untergrund bietet die Pfarreikirche San Clemente. $\mathrm{Zu}$ bestaunen sind zwei übereinander gebaute Kirchen und ein Mithräum in 18 Metern Tiefe. Spätantiker Stierkult im einen Teil von zwei Wohnhäusern aus der Zeit Cäsars. Aus der einst dazwischen liegenden Gasse ist ein schmaler Stollen geworden. Hinter Ziegelöffnungen rauscht ein Zulauf der Cloaca Maxima mit der die Etrusker von 2600 Jahren das Gebiet des späteren Forums trocken legten. Ab dem «Augusteischen Jahr 2000, werden weitere Kaiserforen und die Wohnhäuser von Augustus und Livia mit ihren Wandfresken zugänglich. Wie die zahlreichen früheren Kirchen und Kapellen belegen, hat das frühe Christentum nahtlos die Insignien der Macht übernommen. Von Kaisern gefördert, versieht der neue Reichskult die Tempelzeremonien und Gewänder, die Säulen aus Porphyr und Granit, die Kapitelle und Mosaiken und den Marmor auf Böden und Wänden, mit neuem Inhalt. Das imperiale Vorbild überdauert die lange Chaoszeit und Stagnation nach dem Ende Westroms. Humanistenda Cortona erfinden die neue Architektursprache des Barocks für die Paläste und Kirchen des folgenden Jahrhunderts. Doch erst um 1955 wird der Wasserverbrauch der Einwohner wieder den Stand von der Zeit Trajans, im Jahr 100 n. Chr., erreichen.

Die Kulissen der römischen Kaiserzeit dienen Mussolini als historische Legitimation eines faschistischen Imperiums. Rom wird erneut umgebaut, Gebäude versetzt und Quartiere abgerissen, die antiken Kaiserforen freigelegt, die Märkte Trajans und das Marcellus-Theater wiederhergestellt und teilweise ergänzt. Das ideologisierte Bauprogramm machte aus den republikanischen Liktoren die Symbole dieser RomIdeologie. Der mythische Gründungstag am 21. April 753 n. Chr. wird zum staatlichen Feiertag erklärt.

Auch 70 Jahre nach dem Tod des Duce wirkt der Mythos von Rom auf vielfältige Weise. Ein gewöhnlicher Schachtdeckel, mit der Prägung SPQR, SenatusPopulusQue-Romanus, ist keine Seltenheit. Ein Campus mondiale dell' Umanesimo a Roma wird ab 2015 jährlich 120 ausgewählte Studenten aus allen Nationen aufnehmen. «ll latino torna in Campus» titelt der Messaggero vom 10.11.2014 das Ereignis. Herz des Unternehmens ist die Accademia Vivarium Novum, eine Sommerschule, die das Latein wieder zur Weltsprache erheben möchte. Ableger existieren in China, Spanien, Kroatien, USA und Brasilien. In Rom werden Studenten die Sprache Ciceros während achtwöchigen Intensivkursen nach den Methoden der Akademie erlernen. «Inserito scidulam quaeso» befiehlt der Bankomat im Vatikan den Kunden. Fortgeschrittene lesen den Harrius Potter, nach Bedarf auch altgriechisch, und wer Radiophonia Finnica generalis empfängt, darf die Nachrichten aus Helsinki lateinisch anhören. Lateiner aller Länder, vereinigt euch zur UNESCO-anerkannten Bewegung. Wer etwas auf sich hält, schreibt das aktuelle Kalenderjahr ab urbe condita, also $753+$ 2014 = MMDCCLXVII. Quod erat demonstrandum. 